\title{
ChemComm
}

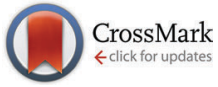

Cite this: Chem. Commun., 2016, 52,12889

Received 14th July 2016,

Accepted 29th September 2016

DOI: $10.1039 / c 6 c c 05796 a$

www.rsc.org/chemcomm

\section{Enzymatic synthesis and reverse transcription of RNAs incorporating 2'-O-carbamoyl uridine triphosphate $\dagger$}

\author{
Yoshiaki Masaki, Hyugo Ito, Yuki Oda, Kazufumi Yamazaki, Nobuhiro Tago, \\ Kentaro Ohno, Nozomi Ishii, Hirosuke Tsunoda, Takashi Kanamori, Akihiro Ohkubo, \\ Mitsuo Sekine and Kohji Seio*
}

\begin{abstract}
Enzymatic synthesis and the reverse transcription of RNAs containing 2 '-O-carbamoyl uridine were evaluated. A mild acidic deprotection procedure allowed the synthesis of $2^{\prime}$-O-carbamoyl uridine triphosphate $\left(U_{c m} T P\right)$. $U_{c m} T P$ was incorporated correctly into long RNAs, and its fidelity during reverse transcription using SuperScript III was sufficient for RNA aptamer selection.
\end{abstract}

Chemical modifications on RNA and DNA aptamers improve their biostability and affinity with targets of interest. ${ }^{1-11}$ To introduce modifications, chemical or enzymatic synthesis of RNA aptamers is utilized. Chemical synthesis can introduce a wide variety of chemical modifications into RNA aptamers that are selected using canonical nucleoside triphosphates (NTPs). However, because the chemical modifications sometimes diminish the activity of the initial unmodified RNA aptamer, optimal chemical modifications should be identified after structure-activity analyses for many synthetic RNA aptamer derivatives. On the other hand, because enzymatic synthesis is compatible with RNA aptamer selection, the selected aptamers are expected to have an optimized structure without additional optimization. To expand the usefulness of this enzymatic synthesis strategy, it is important to develop modified nucleosides that can be substrates of the polymerases used in the aptamer selection procedure.

Among various chemical modifications, ${ }^{2,10,12}$ those at the $2^{\prime}$-position are promising because they can improve the resistance of oligonucleotides toward both enzymatic and chemical degradation. ${ }^{13-16}$ In addition, $2^{\prime}$-modifications can change RNA structure flexibility, ${ }^{17}$ hydration, ${ }^{18-20}$ and base pairing selectivity. ${ }^{21}$ Despite their importance, only a limited number of $2^{\prime}$-modified NTPs can be applied for enzymatic syntheses. ${ }^{10}$ For example, natural T7 RNA polymerase or the Y639F mutant ${ }^{22}$ can incorporate modified nucleosides having single heavy atom substituents at the $2^{\prime}$-position such as $2^{\prime}$-fluoro, ${ }^{23} 2^{\prime}$-amino, ${ }^{23}$ and $2^{\prime}$-thiol. ${ }^{24}$ The Y639F mutant

Department of Life Science and Technology, Tokyo Institute of Technology, J2-16, 4259 Nagatsuta-cho, Midori-ku, Yokohama, Japan. E-mail: kseio@bio.titech.ac.jp $\dagger$ Electronic supplementary information (ESI) available. See DOI: 10.1039/ c6cc05796a

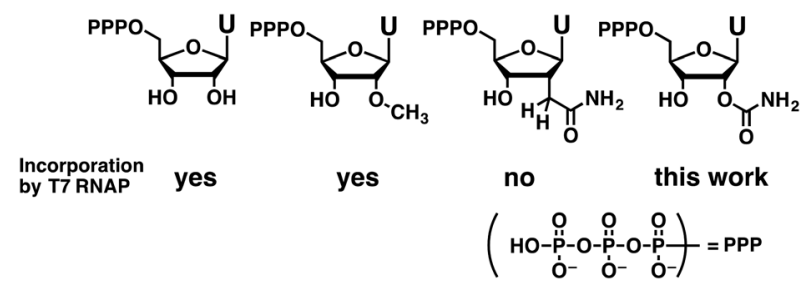

Fig. 1 Chemical modifications for the enzymatic synthesis of RNA.

allows incorporation of larger $2^{\prime}$-O-methyl ${ }^{25}$ or $2^{\prime}$-hydroxymethyl groups $^{26}$ that have two heavy atoms at the $2^{\prime}$-position. In the case of substituents having three heavy atoms, incorporation of 2 -azido nucleosides by $\mathrm{Y} 639 \mathrm{~F} / \mathrm{H} 784 \mathrm{~A}$ T7 RNA polymerase is reported. $^{27}$ However, incorporation of a $2^{\prime}$ - $C$-carbamoylmethyl group, which is a four heavy-atom substituent, was unsuccessful (Fig. 1). ${ }^{26}$

Here, we report that a new NTP having a $2^{\prime}$-O-carbamoyl group, which is a four heavy-atom substituent, can be incorporated into RNA by a natural T7 RNA polymerase. Previously, we reported the chemical synthesis of RNA containing $2^{\prime}$-O-carbamoyl uridine $\left(\mathrm{U}_{\mathrm{cm}}\right)$. The introduction of $\mathrm{U}_{\mathrm{cm}}$ improved nuclease resistance and unexpectedly enhanced G-U base pair formation. ${ }^{14,21}$ Molecular dynamics simulations suggested the additional hydrogen bonding of a 2 -O-carbamoyl moiety with the 2-amino group on guanosine (Fig. S1-S3, ESI $\dagger)^{17,21,28-33}$ This unique effect of $\mathrm{U}_{\mathrm{cm}}$ might facilitate the formation of various RNA secondary structures including G-U mismatches. Here, we report the synthesis of 2'-O-carbamoyl uridine triphosphate $\left(\mathrm{U}_{\mathrm{cm}} \mathrm{TP}\right)$ and its applicability toward aptamer selection.

Although the 2'-O-carbamoyl group remains intact under neutral or weakly acidic conditions, it migrates to the adjacent 3 -hydroxyl group under basic conditions such as $28 \%$ ammonium hydroxide treatment (Fig. S4, ESI $\dagger$ ). Thus, for the synthesis of $\mathrm{U}_{\mathrm{cm}} \mathrm{TP}$ (Scheme 1), we protected the $3^{\prime}$-hydroxyl group with tert-butyldimethylsilyl ether (TBS) and removed this group under non-basic conditions. 5'-O-Dimethoxytrityl-2'-O-carbamoyl uridine (2) was synthesized by following a synthetic scheme reported 


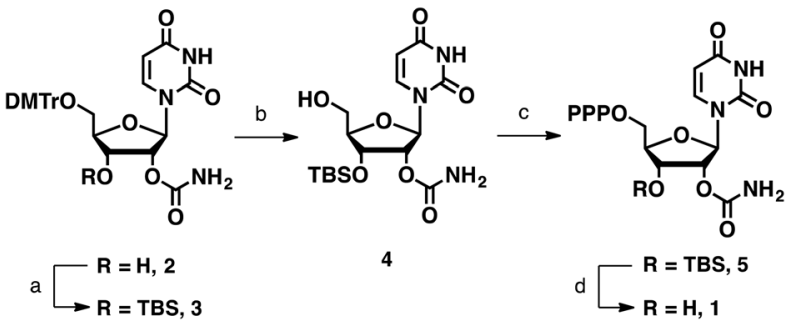

Scheme 1 Synthesis of $2^{\prime}$-O-carbamoyl uridine triphosphate $\left(\mathrm{U}_{\mathrm{cm}} T \mathrm{TP}\right)$ Reaction conditions: (a) TBSCl, imidazole, dimethyl formamide (DMF), room temperature (rt), $14 \mathrm{~h}$; (b) $4 \%$ trifluoroacetic acid, $\mathrm{CH}_{2} \mathrm{Cl}_{2}, \mathrm{rt}, 30 \mathrm{~min}, 63 \%$ (2 steps); (c) salicyl phosphorochloridite, pyridine-1,4-dioxane, rt, $10 \mathrm{~min}$, then pyrophosphate, tributylamine, DMF, rt, 10 min, then $\mathrm{I}_{2}$, pyridine- $\mathrm{H}_{2} \mathrm{O}, \mathrm{rt}$, $15 \mathrm{~min}$ (61\%); and (d) citric acid buffer ( $\mathrm{pH} 3.0), 30{ }^{\circ} \mathrm{C}, 24 \mathrm{~h}, 78 \%$.

previously. ${ }^{21}$ After TBS-protection to give 3 and dimethoxytrityldeprotection from 3 , the $5^{\prime}$-free derivative 4 was synthesized. Subsequently, the $5^{\prime}$-triphosphate moiety of 5 was introduced by Eckstein's method. ${ }^{34}$ Then, removal of the TBS group of $\mathbf{5}$ was tested using fluoride sources such as tetrabutylammonium fluoride and triethylammonium trifluoride. However, they gave only complexed mixtures (see Table S1 for detailed conditions, ESI $\dagger$ ).

Previously, Kawahara et al. found that the 2'-O-TBS group on oligoribonucleotides could be removed by an $8 \%$ acetic acid aqueous solution because of the neighboring effect of the internucleotidic phosphate. ${ }^{35}$ Thus, we speculated that the $3^{\prime}$-O-TBS group on NTPs could also be deprotected under weakly acidic conditions because of the presence of the $5^{\prime}$-triphosphate. After screening various weakly acidic conditions, we found that pH 3.0 citrate buffer was suitable for deprotection of the TBS group (Fig. S5, ESI†). Under this mild condition, we could synthesize $\mathrm{U}_{\mathrm{cm}} \mathrm{TP}(\mathbf{1})$ in $78 \%$ yield without any detectable migration product.

Initial transcription experiments were performed with T7 RNA polymerase. We used a synthetic RNA labeled at the $5^{\prime}$-terminus with fluorescein as a reference product (Fig. 2a, lane 1). RNA transcription using ATP, GTP, CTP (20\% FAM-CTP), and UTP was performed as a positive control reaction (Fig. 2a, lane 2). For a negative control, the transcription reaction was performed in the absence of UTP. This reaction showed possible mis-incorporated products when 1 was not incorporated by T7 RNA polymerase (Fig. 2a lane 4). As expected, lane 4 did not show any detectable full-length product.

Lane 3 in Fig. 2a shows the product of the RNA transcription reaction using ATP, GTP, CTP (20\% FAM-CTP), and 1. Surprisingly, 1 was incorporated smoothly even by wild-type T7 RNA polymerase. The ratio of the full-length products between lanes 2 and 3 , estimated by the gel band intensities, was 0.76 . This result indicated that 1 could be used as a substrate for T7 RNA polymerase. The $24 \%$ decrease of the full-length product might be explained by steric repulsion with the $\mathrm{T} 7$ polymerase active site because the X-ray structure indicated the presence of only a small space around the $2^{\prime}$-oxygen atom. ${ }^{36,37}$

To confirm the incorporation of $\mathbf{1}$, we synthesized a shorter 15mer RNA (5'-pppGGGCCAA- $\mathrm{U}_{\mathrm{cm}}$-ACAAAGA-3'), purified it by gel electrophoresis, and determined the molecular weight of a)
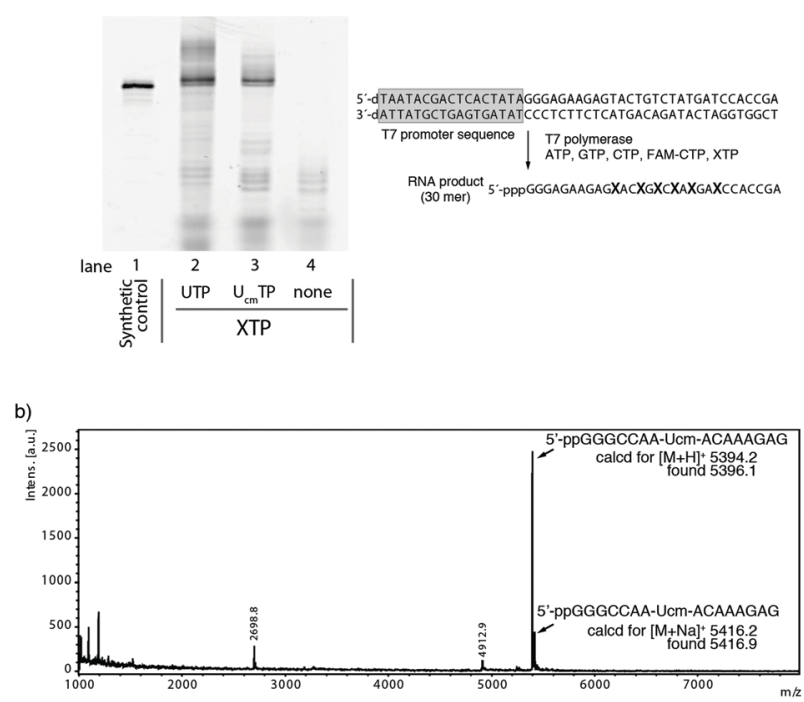

Fig. 2 Analysis of RNA products transcribed by T7 RNA polymerase. (a) Lane 1: 5'-fluorescein (FAM) labeled synthetic RNA. Lane 2: RNA transcript with ATP, GTP, CTP, FAM-CTP, and UTP. Lane 3: RNA transcript with ATP, GTP, CTP, FAM-CTP, and 1. Lane 4: RNA transcript with ATP, GTP, CTP, and FAM-CTP. (b) MALDI-TOF MS spectrum of RNA products. Template duplex: 5' -TCT TTG TAT TGG CCC TAT AGT GAG TCG TAT TA/5'-TAA TAC GAC TCA CTA TAG GGC CAA TAC AAA GA.

the main product by MALDI-TOF mass analysis. As shown in Fig. $2 \mathrm{~b}$, the mass data suggested that the molecular weight of the main product was 5396.1. This corresponded to ppGGGCCAA$\mathrm{U}_{\mathrm{cm}}$-ACAAAGAG which contains additional guanosine residues at the $3^{\prime}$-terminus ${ }^{38}$ and lacks the gamma phosphate of the $5^{\prime}$-guanosine triphosphate.

To confirm the sequences of RNAs synthesized by enzymatic incorporation of $\mathbf{1}$, we attempted to sequence each RNA after its conversion into the corresponding cDNA. For this purpose, the fidelity of reverse transcription of RNA containing $\mathrm{U}_{\mathrm{cm}}$ was evaluated. The RNA template containing $\mathrm{U}_{\mathrm{cm}}$ was chemically synthesized according to a method reported previously (Fig. 3a). ${ }^{21}$ Single nucleotide extension experiments were performed with SuperScript III under standard conditions with one of the four natural deoxy (d)NTPs (Fig. 3a). After the enzymatic reaction, the products were analyzed by polyacrylamide gel electrophoresis. Lane 1 is the FAM-labeled cDNA primer. Lanes 2 to 5 are the positive controls reverse transcribed with the natural RNA template using one of the four natural dNTPs. Lanes 6 to 9 are experiments with the RNA template containing a $\mathrm{U}_{\mathrm{cm}}$ residue. Interestingly, dATP was selectively incorporated opposite the template $U_{\mathrm{cm}}$ residue (lane 6 versus lanes 7, 8, and 9).

The reverse transcription experiments using the full RNA sequence with the four natural dNTPs are shown in Fig. 3b. Although the efficiency of reverse transcription on the $\mathrm{U}_{\mathrm{cm}}$ containing template was lower than the natural RNA template (lane 3 versus lane 5), the prolonged reaction time reduced the residual unreacted cDNA primer (lane 6).

To evaluate the applicability of this method to the synthesis of longer RNA aptamers, and the fidelity of reverse transcription, we used T7 RNA polymerase to enzymatically synthesize a 


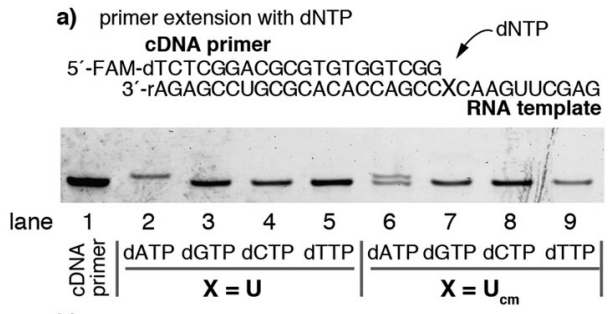

b) primer extension with dNTPs

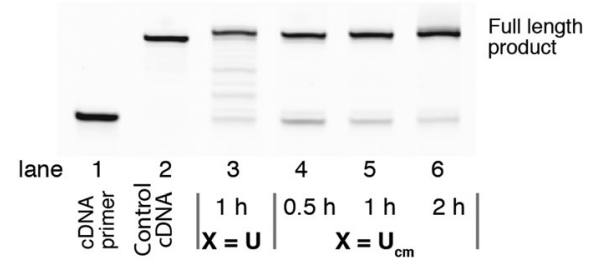

Fig. 3 The fidelity of reverse transcription by SuperScript III. (a) Single nucleotide insertion of dNTP. (b) Primer extension with dNTPs.

99mer of RNA containing $\mathrm{U}_{\mathrm{cm}}$ residues. The sequence was a known RNA aptamer, Spinach. ${ }^{39}$ Spinach RNA induces fluorescence upon binding of (Z)-4-(3,5-difluoro-4-hydroxybenzylidene)-1,2dimethyl-1H-imidazol-5(4H)-one. First, the T7 RNA polymerasemediated transcription reaction was performed with $\mathbf{1}$ and the chemically synthesized DNA duplex coding the Spinach sequence (the entire sequence is shown in the ESI $\dagger$ ). The reaction mixtures were treated with DNase I to remove the DNA duplex, and then analyzed by gel electrophoresis (Fig. $4 \mathrm{~b}$ ). The first and second right lanes of Fig. $4 \mathrm{~b}$ clearly showed that the 99mer RNA was obtained. The RNA product transcribed with $\mathrm{U}_{\mathrm{cm}} \mathrm{TP}$ showed comparable binding affinities to DFHBI with a canonical Spinach aptamer (Fig. S6, ESI $\dagger$ ). To confirm the incorporation of 1, a portion of the RNA transcript was hydrolyzed enzymatically by snake venom phosphodiesterase and alkaline phosphatase. The completely digested mixtures were applied to reversed phase-HPLC. The result showed a pattern of A, G, C, and $\mathrm{U}_{\mathrm{cm}}$ nucleosides without any detectable U (Fig. 4c). This clearly indicated that the RNA transcript was not generated by undetectable amounts of UTP contamination. Next, the remaining RNA transcripts were reverse transcribed by SuperScript III, and the polymerase chain reaction was performed to amplify the reverse transcribed cDNA, which was then sequenced (Fig. 4d). The sequence data of the transcript obtained by using $\mathbf{1}$ (lower panel) clearly shows a pattern similar to that obtained from the transcript using UTP (upper panel). Thus, the transcript sequence was confirmed. We also performed a transcription reaction with the DNA template containing randomized 20 nucleotides $\left(\mathrm{N}_{20}\right)$ and confirmed the products by gel electrophoresis (Fig. S7, ESI $\dagger$ ). From these results, we concluded that $\mathrm{U}_{\mathrm{cm}} \mathrm{TP}$ could be applicable for RNA aptamer selection.

In summary, we have developed a new synthetic method for NTP 1 having a base-labile moiety. This method could be useful for the synthesis of more complex base-labile NTPs. We demonstrated the applicability of using $\mathbf{1}$ for transcription by T7 RNA polymerase and reverse transcription. Compound $\mathbf{1}$ was incorporated specifically opposite to the A base and was sufficient to a)

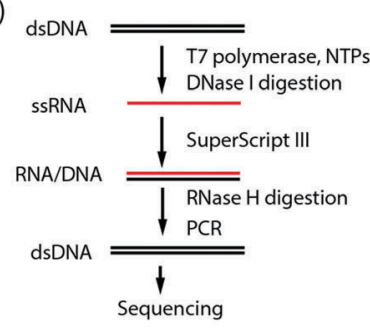

b)
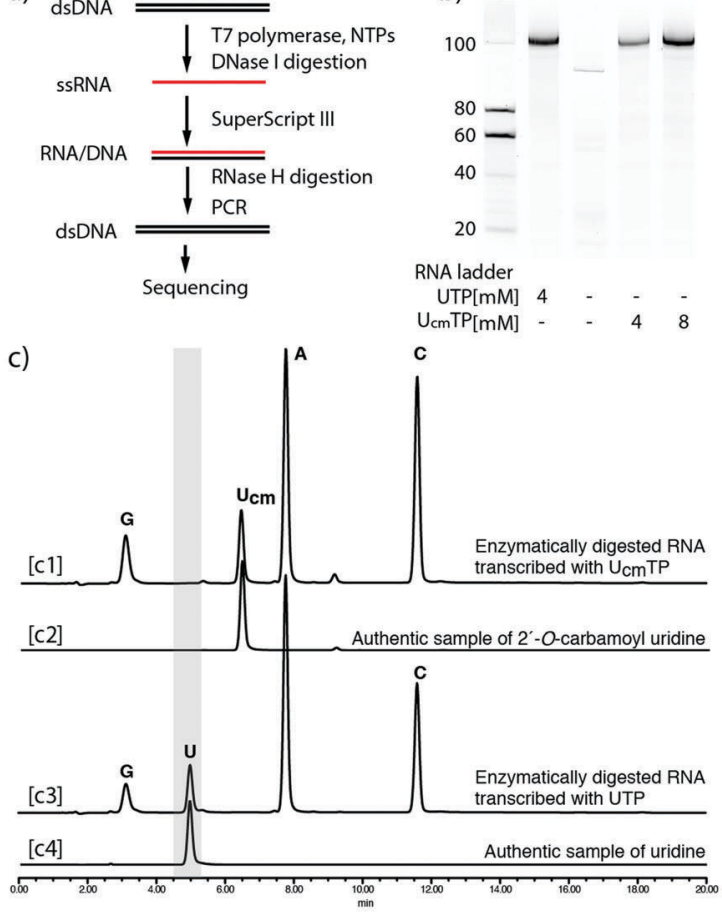

d)
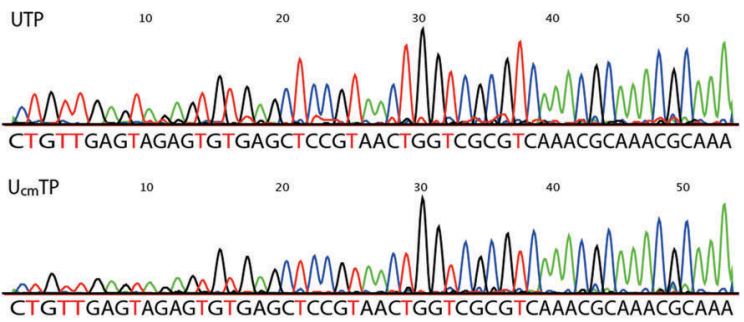

Fig. 4 Evaluation of applicability for RNA aptamer selection. (a) Flow chart of the experimental procedure. (b) Gel electrophoresis of RNA products transcribed by T7 RNA polymerase. (c) HPLC charts of enzymatically digested RNA products and authentic samples. [c1] Enzymatically digested RNA transcribed with $U_{c m} T P$. [c2] Authentic sample of $U_{c m}$. [c3] Enzymatically digested RNA transcribed with $U_{c m}$ TP. [c4] Authentic sample of $U$. (d) Sequence data after PCR amplification of reverse transcribed DNA. The upper row is from an RNA product transcribed with UTP. The lower row is from an RNA product transcribed with $U_{\mathrm{cm}} T P$.

transcribe the 99mer of structured RNA. It should be noted that the carbamoyl modification of $\mathbf{1}$ is the sterically largest substituent on the $2^{\prime}$-hydroxyl group that is thus far allowed by T7 polymerase. Moreover, dATP was incorporated correctly against the $\mathrm{U}_{\mathrm{cm}}$ residue during reverse transcription. This precise incorporation of 1 by T7 RNA polymerase and high fidelity in reverse transcription make $\mathbf{1}$ an excellent candidate for the modified NTP, and useful for the enzymatic selection of modified RNA aptamers.

We reported previously that the $\mathrm{U}_{\mathrm{cm}}$ residue enhanced $\mathrm{G}-\mathrm{U}$ base pair formation in RNA duplexes. ${ }^{21}$ The G-U base pair plays a crucial role in structure formation and the activity of various functional RNAs such as tRNA, ${ }^{40,41}$ rRNA, ${ }^{42-44}$ and group I selfsplicing introns. ${ }^{45}$ In addition, most RNA secondary structure prediction software treats the $\mathrm{G}-\mathrm{U}$ base pair as a canonical base pair. ${ }^{46,47}$ Because $U_{\mathrm{cm}}$ facilitates $\mathrm{G}-\mathrm{U}$ base pair formation, we 
believe $\mathrm{U}_{\mathrm{cm}} \mathrm{TP}$ will be useful to explore a wider range of RNA secondary structures in aptamer selection.

This work was supported by the Japan Society for the Promotion of Science (grant numbers 26810086, 15H01062, 15K13738, and 26288075). DNA sequencing was supported by the Biomaterials Analysis Division, Technical Department, Tokyo Institute of Technology.

\section{Notes and references}

1 T. Chen, N. Hongdilokkul, Z. Liu, R. Adhikary, S. S. Tsuen and F. E. Romesberg, Nat. Chem., 2016, 8, 556-562.

2 S. A. Lapa, A. V. Chudinov and E. N. Timofeev, Mol. Biotechnol., 2016, 58, 79-92.

3 N. Tarashima, T. Sumitomo, H. Ando, K. Furukawa, T. Ishida and N. Minakawa, Org. Biomol. Chem., 2015, 13, 6949-6952.

4 Y. Imaizumi, Y. Kasahara, H. Fujita, S. Kitadume, H. Ozaki, T. Endoh, M. Kuwahara and N. Sugimoto, J. Am. Chem. Soc., 2013, 135, 9412-9419.

5 M. Kimoto, R. Yamashige, K. Matsunaga, S. Yokoyama and I. Hirao, Nat. Biotechnol., 2013, 31, 453-457.

6 F. Tolle and G. Mayer, Chem. Sci., 2013, 4, 60.

7 A. D. Keefe, S. Pai and A. Ellington, Nat. Rev. Drug Discovery, 2010, 9, 537-550.

8 E. W. Ng, D. T. Shima, P. Calias, E. T. Cunningham, Jr., D. R. Guyer and A. P. Adamis, Nat. Rev. Drug Discovery, 2006, 5, 123-132.

9 G. Kolb, S. Reigadas, C. Boiziau, A. van Aerschot, A. Arzumanov, M. J. Gait, P. Herdewijn and J. J. Toulme, Biochemistry, 2005, 44, 2926-2933.

10 L. H. Lauridsen, J. A. Rothnagel and R. N. Veedu, ChemBioChem, $2012,13,19-25$

11 X. M. Ren, A. H. El-Sagheer and T. Brown, Nucleic Acids Res., 2016, 44, e79.

12 T. Carell, C. Brandmayr, A. Hienzsch, M. Muller, D. Pearson, V. Reiter, I. Thoma, P. Thumbs and M. Wagner, Angew. Chem., Int. Ed., 2012, 51, 7110-7131.

13 A. Demesmaeker, R. Haner, P. Martin and H. E. Moser, Acc. Chem. Res., 1995, 28, 366-374.

14 K. Seio, M. Tokugawa, T. Kanamori, H. Tsunoda, A. Ohkubo and M. Sekine, Bioorg. Med. Chem. Lett., 2012, 22, 2470-2473.

15 T. Yamada, Y. Masaki, N. Okaniwa, T. Kanamori, A. Ohkubo, H. Tsunoda, K. Seio and M. Sekine, Org. Biomol. Chem., 2014, 12, 6457-6464.

16 T. P. Prakash, Chem. Biodiversity, 2011, 8, 1616-1641.

17 Y. Masaki, R. Miyasaka, A. Ohkubo, K. Seio and M. Sekine, J. Phys. Chem. B, 2010, 114, 2517-2524.
18 R. Pattanayek, L. Sethaphong, C. L. Pan, M. Prhave, T. P. Prakash, M. Manoharan and M. Egli, J. Am. Chem. Soc., 2004, 126, 15006-15007.

19 M. Egli, G. Minasov, V. Tereshko, P. S. Pallan, M. Teplova, G. B. Inamati, E. A. Lesnik, S. R. Owens, B. S. Ross, T. P. Prakash and M. Manoharan, Biochemistry, 2005, 44, 9045-9057.

20 M. Egli and P. S. Pallan, Chem. Biodiversity, 2010, 7, 60-89.

21 K. Seio, R. Tawarada, T. Sasami, M. Serizawa, M. Ise, A. Ohkubo and M. Sekine, Bioorg. Med. Chem., 2009, 17, 7275-7280.

22 R. Sousa and R. Padilla, EMBO J., 1995, 14, 4609-4621.

23 H. Aurup, D. M. Williams and F. Eckstein, Biochemistry, 1992, 31, 9636-9641.

24 K. Raines and P. A. Gottlieb, RNA, 1998, 4, 340-345.

25 R. Padilla and R. Sousa, Nucleic Acids Res., 1999, 27, 1561-1563.

26 J. B. Pavey, A. J. Lawrence, I. A. O'Neil, S. Vortler and R. Cosstick, Org. Biomol. Chem., 2004, 2, 869-875.

27 R. Padilla and R. Sousa, Nucleic Acids Res., 2002, 30, e138.

28 W. D. Cornell, P. Cieplak, C. I. Bayly, I. R. Gould, K. M. Merz, D. M. Ferguson, D. C. Spellmeyer, T. Fox, J. W. Caldwell and P. A. Kollman, J. Am. Chem. Soc., 1995, 117, 5179-5197.

29 J. A. McDowell, L. Y. He, X. Y. Chen and D. H. Turner, Biochemistry, 1997, 36, 8030-8038.

30 J. Wang, R. M. Wolf, J. W. Caldwell, P. A. Kollman and D. A. Case, J. Comput. Chem., 2004, 25, 1157-1174.

31 Y. Masaki, R. Miyasaka, K. Hirai, H. Tsunoda, A. Ohkubo, K. Seio and M. Sekine, Chem. Commun., 2012, 48, 7313-7315.

32 H. J. C. Berendsen, J. P. M. Postma, W. F. Vangunsteren, A. Dinola and J. R. Haak, J. Chem. Phys., 1984, 81, 3684-3690.

33 T. Darden, D. York and L. Pedersen, J. Chem. Phys., 1993, 98, 10089.

34 J. Ludwig and F. Eckstein, J. Org. Chem., 1989, 54, 631-635.

35 S.-i. Kawahara, T. Wada and M. Sekine, J. Am. Chem. Soc., 1996, 118, 9461-9468.

36 Y. Huang, F. Eckstein, R. Padilla and R. Sousa, Biochemistry, 1997, $36,8231-8242$.

37 T. A. Steitz, Curr. Opin. Struct. Biol., 2009, 19, 683-690.

38 J. F. Milligan, D. R. Groebe, G. W. Witherell and O. C. Uhlenbeck, Nucleic Acids Res., 1987, 15, 8783-8798.

39 J. S. Paige, K. Y. Wu and S. R. Jaffrey, Science, 2011, 333, 642-646.

40 Y. M. Hou and P. Schimmel, Nature, 1988, 333, 140-145.

$41 \mathrm{~W}$. McClain and K. Foss, Science, 1988, 240, 793-796.

42 D. Gautheret, D. Konings and R. R. Gutell, RNA, 1995, 1, 807-814.

43 S. A. White, M. Nilges, A. Huang, A. T. Brunger and P. B. Moore, Biochemistry, 1992, 31, 1610-1621.

44 M. Szymanski, M. Z. Barciszewska, V. A. Erdmann and J. Barciszewski, Mol. Biol. Evol., 2000, 17, 1194-1198.

45 S. A. Strobel and T. R. Cech, Biochemistry, 1996, 35, 1201-1211.

46 M. Andronescu, V. Bereg, H. H. Hoos and A. Condon, BMC Bioinf., 2008, 9, 340.

47 D. H. Mathews, J. Sabina, M. Zuker and D. H. Turner, J. Mol. Biol., 1999, 288, 911-940. 